\title{
Saving logistics transportation costs in the era of globalization for firms
}

\author{
Peter Majercak ${ }^{1, *}$ \\ ${ }^{1}$ University of Zilina, FPEDAS, Department of Economy, Univerzitna 1, 01026 Zilina
}

\begin{abstract}
The paper of the conference is focused of transportation costs and their saving for firms in the era of globalization. Transportation requires the use of resources-labor, equipment, fuel, and infrastructure. The cost of transportation is the use of these resources. Some of these resources are purchased directly by the users of transportation-for example, fuel purchased by households for automobile travel. Many resources are purchased by firms that provide transportation services-for example, labor purchased by a railroad or fuel bought by a trucking company. In addition, governments (federal, state and local) provide most of the transportation infrastructure, such as highways. The main body of the paper is orientated to practical study of transportation logistic costs and optimization. In this case, we are considering the supply in logistic chain as follows: supplier $\rightarrow$ carrier $\rightarrow$ manufacturing company. The supplier represents the semi-product producer. The aim of this paper is to compare classic approach, when every part tracks its costs isolated a try to minimize them, with the system (logistic) approach, where the whole supply chain is optimized. Logistics costs are understood as expenses incurred from performing logistics activities, and from having the infrastructure, capacity or the readiness to perform logistic activities during a certain period of time.
\end{abstract}

\section{Introduction}

Currently available on all major markets competitive, the companies are high requirements. Enterprise to survive in this environment, they must gain a competitive advantage over others. One of the competitive advantages may become a well designed logistics system. Logistics, as a scientific discipline and management tool, has recently attaches increasing importance. It deals with the optimal coordination, harmonization, linking and optimizing the flow of raw materials, semi-finished products and services, but the flow of information and finance. In all these areas is bound by a large number of funds, their planning and management is therefore very important for businesses. [1]

Between the most important areas of logistics planning and management include inventory area. They provide smooth running of production and provide much room to maneuver. If excess inventory, bind many funds that the company could use otherwise. If the lack of inventory, cause difficulties in production. [2] Cessation of production or

\footnotetext{
* Corresponding author: peter.majercak@fpedas.uniza.sk
} 
rebuilding of machinery represents the company is not only financial, but also the loss of time. To such cases in the enterprise avoid, requires management to enterprise careful planning and monitoring of stocks.

Since logistics advanced from 1950s, there were numerous researches focused on this area in different applications. Due to the trend of nationalisation and globalisation in recent decades, the importance of logistics management has been growing in various areas. For industries, logistics helps to optimise the existing production and distribution processes based on the same resources through management techniques for promoting the efficiency and competitiveness of enterprises.

The key element in a logistics chain is transportation system, which joints the separated activities. Transportation occupies one-third of the amount in the logistics costs and transportation systems influence the performance of logistics system hugely. Transporting is required in the whole production procedures, from manufacturing to delivery to the final consumers and returns. Only a good coordination between each component would bring the benefits to a maximum.

\subsection{History and Advancement of Logistics}

Logistics was initially a military activity concerned with getting soldiers and munitions to the battlefront in time for flight, but it is now seen as an integral part of the modern production process. The main background of its development is that the recession of America in the 1950s caused the industrial to place importance on goods circulations. The term, logistics, was initially developed in the context of military activities in the late 18th and early 19th centuries and it launched from the military logistics of World War II. [3]

The probable origin of the term is the Greek logistikos, meaning 'skilled in calculating'. (BTRE, 2001) Military definitions typically incorporate the supply, movement and quartering of troops in a set. And now, a number of researches were taken and made logistics applications from military activities to business activities. Business logistics was not an academic subject until the 1960s. A key element of logistics, the trade-off between transport and inventory costs, was formally recognized in economics at least as early as the mid-1880s.

\section{Integrated Logistics Support Elements - Historical View}

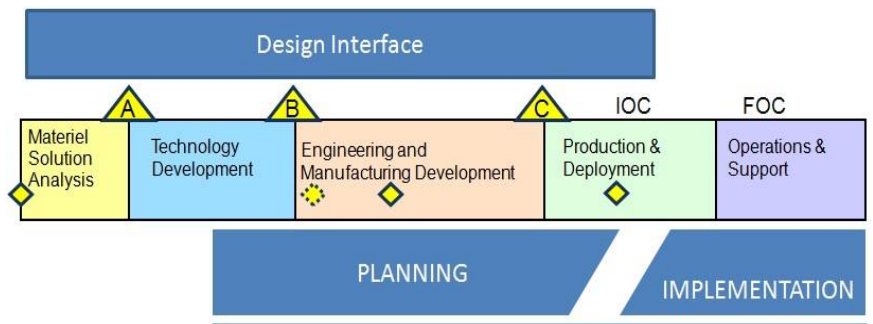

Maintenance Planning, Supply Support, PHS\&T, Technical

Data, Support Equipment, Training \& Training Support,

Manpower \& Personnel, Facilities \& Infrastructure,

Computer Resources

Fig. 1. Historical logistics development

Before the 1950s, logistics was under the dormant condition. Production was the main part of the managers concerned, and industry logistics was once regarded as "necessary evil" in this period. During the 1950s to and 1960s, applying new ideas of administration on business was a tendency. Poliak (2019), who thought Logistics was The Economy's 
Dark Continent, regarded the procedure of physical distribution after producing products as the most possible development area in American businesses but also the most neglected area. Lewis's study (cited in Chang, 1998) in 1956 on the role of air transportation in physical distribution was the application of "total cost concept" and it pointed out the notions of tradeoff between inventory and transportation. [4]

From the 1970s onwards, more and more applications and researches of logistics appeared. Due to petroleum price rise in 1973, the effects of logistics activities on enterprises grew. Slow growth of market, pressure of high stagflation, release of transportation control, and competitions of the third world on products and materials all increased the significance of logistics system on planning and business at that time. $[5,6]$

The further tendency of logistics in the early 21 st century is logistics alliance, Third Party Logistics (TPL) and globalised logistics. Logistics circulation is an essential of business activities and sustaining competitiveness, however, to conduct and manage a large company is cost consuming and not economic. Therefore, alliance of international industries could save working costs and cooperation with TPL could specialize in logistics area.

\section{Supply logistics}

Contents of Inbound Logistics is the purchase of basic and auxiliary materials, semifinished products and sub-subcontractors. This cartridge is divided between two departments, namely:

- Procurement Department - principally engaged in the administrative nature of the work, the survey shopping market, opening and closing shopping negotiation, price, and value analysis, management, purchasing, order processing etc.,

- Department of warehouse management and material handling - not only responsible for administrative tasks but also for the physical nature of the tasks associated with the physical flows materials and supplies such as. receipt of material in stock, its follow-up and storage and warehouse management, internal transport but also for planning, directing and control of material flow of information.

Supply is among one of the most important business activities. Ensures Enterprise tangible and intangible factors of production necessary to fulfill his duties. For the enterprise have stocks of both positive and negative meanings. Negative lies primarily in the fact that stocks undertaking binds capital, labor and resources consuming and carries the risk of deterioration; inoperable or sell. On the other hand, the stock settled time, local, capacitive and assortment mismatch between production and consumption, ensure continuity of production process and cover a variety of unforeseen fluctuations. [7]

Any undertaking must consider the advantages and disadvantages of holding inventory in stock, due to their conditions. The advantage of maintaining inventory is to enable the company to achieve the effect of economies of scale, for example, savings resulting from the purchase of a large scale (quantity discounts) and also follows can be achieved by reducing the cost of transport to balance supply and demand - the risk arising from nondelivery to the customer on time performance with an increase in demand (especially in seasonal increase in demand) and provide protection against unforeseen events (eg before depletion of stocks in the case of variable demand, before increasing raw material prices, etc..). [8] 


\section{Optimalization of logistics costs in the global supply chain}

The cost of maintaining inventory costs are related to the amount of inventory in stock. They consist of a series of various cost elements and practical experience suggests that they belong the largest logistics costs. For the purposes of decision-making are important especially those items which vary depending on the volume of stocks. The main cost items stockholding, which depend on the size of the inventory are:

- Capital costs - corresponding to the return which the undertaking of these funds obtained if it is invested in another way, ie if they were not bound in stocks (Cost of the commitment of current assets in stocks) costs of services - including life insurance and taxation of stocks,

- the cost of storing inventory-relate to the cost of the storage area to varies depending on the state of the stock,

- Cost of risk - loss resulting from moral wear, petty theft, transfer within the system and stocks of damage. [9]

\section{Logistics costing has been defined as:}

- identifying different costs that result from servicing customer with particular product mixes; and

- registering, calculating and reporting all logistics costs, which are caused by the business between the dispatch ramps of the suppliers and the receiving ramps of the customers.

Majercak et al. (2015) also use the term supply chain costing, and define that as "...the collection, expense assignment and analysis of cost information across all of the work activities comprising a supply chain for the purpose of identifying opportunities to obtain a competitive advantage through a combination of reduced costs or improved performance."

This definition is also suitable for logistics cost management, when 'supply chain' is replaced with 'intra-company supply chain': the author of this thesis considers that a supply chain extends outside the firm boundaries and includes at least one external partner, either a customer or a supplier. $[10,11]$

The aim of a logistics costing system (or logistics control system is considered to be to 'determine the total cost of specific logistics objectives (outputs) by quantifying the various logistics inputs', i.e. to quantify the resources used in logistics activities (in a given period).

Drawing on this and the other definitions presented here, logistics costing (/cost management) system can therefore be defined as

"...a system comprising the rules, routines and responsibilities for registering, calculating and reporting all logistics costs, which are caused by the business between the dispatch ramps of the suppliers and the receiving ramps of the customers."

If a cost analysis extends the legal company borders and includes suppliers or customers, it may be considered supply chain costing.

\section{Total cost of logistics and supply chain cost}

Logistics costs here are understood as expenses incurred from performing logistics activities, and from having the infrastructure, capacity or the readiness to perform logistic activities during a certain period of time. Unlike in external reporting for financial purposes (e.g. for stock owners), there are no set rules regulating precisely which expenses should be included as logistics costs.

It largely depends on what activities the firm defines as logistics or supply chain. Poliak (2019) provide an allencompassing definition of logistics costs:

"The logistics costs KLog [€/planning period] are the total operating costs of a single logistic performance station, a logistics profit center, the logistics network of a company or a of a logistics service provider." 
This definition aptly describes the broad range of possibilities rganizing logistics costing. On the one hand, 'a single logistics performance station' is probably the smallest unit in a company where costs are measured and recorded; but on the other hand the logistics network of a company or a LSP is likely to extend outside the legal borders of the company and may include dozens of independent organizations. [13,14,15]

\section{Practical case of transport costs}

In this case, we are considering the supply in logistic chain as follows: supplier $\rightarrow$ carrier $\rightarrow$ manufacturing company. The supplier represents the semi-product producer. The aim of this study is to compare classic approach, when every part tracks its costs isolated a try to minimize them, with the system (logistic) approach, where the whole supply chain is optimized.

\section{Values for calculation:}

$Q=90000 \mathrm{u} / \mathrm{y}$ - total volume of supplied semi-products, $\quad f_{l}$ - frequency (per year) of supplies, $\quad f_{2}$ - frequency of supplies according to carrier, $f_{3}-$ frequency of supplies according to producer, $n d=40 €$ - supplier's costs to the expedition of one supply, $\quad s_{d}=0,8 €$ - store costs per unit per year by supplier, $\quad n v=18 €-$ producer's costs to order one supply, $\quad s_{v}=1 €-$ store costs per unit per year by producer, $\quad l=40$ $\mathrm{km}$ - distance from producer to supplier, $n_{t}=0,32 € / \mathrm{km}$ - transport rate, $A=54080 € / \mathrm{y}$ yearly amortisation of procurement costs of transport system by $f_{2}=1$.

\section{Isolated optimization - supplier}

By the supplier we are talking about costs to procure semi-products supply and their storage. If we mark the volume in one supply $q_{d}$, then supplier's costs $N_{d}$ equal:

$$
\begin{gathered}
N_{d}=\frac{Q}{q_{d}} \cdot n_{d}+\frac{q_{d}}{2} \cdot s_{d} \text {, or according to frequency: } \quad f_{1}=\frac{Q}{q_{d}} \\
N_{d}=f_{1} \cdot n_{d}+\frac{Q}{2 \cdot f_{1}} \cdot s_{d}
\end{gathered}
$$

We can determine the optimal supply frequency from the annulated first derivation:

$$
\begin{gathered}
\frac{d N_{d}}{d f_{1}}=0 \\
n_{d} \frac{Q}{2 f_{1}^{2}} \cdot s_{d}=0 \\
f_{1}=\sqrt{\frac{Q \cdot s_{d}}{2 \cdot n_{d}}}=\sqrt{\frac{90000 \cdot 0,8}{2 \cdot 40}=30}
\end{gathered}
$$

\section{Isolated optimization - carrier}

The carrier performs particular transport system with an optimal frequency. There are two opposite items in the transport costs. By high frequency, vehicles with small item capacity are used. They will be used effectively but will ride o lot of kilometres. In the case of small volume of supplies, high-capacity vehicles will ride less kilometres but capacities will not be used sufficiently.

It will cost higher costs $\frac{A}{f_{2}}$. This situation is explained by cost function: 


$$
\begin{gathered}
N_{\mathrm{t}}=\frac{A}{2 f_{2}}+f_{2} \cdot l \cdot n_{D} \\
f_{2}=\sqrt{\frac{A}{l \cdot n_{\mathrm{t}}}}=\sqrt{\frac{54080}{40.0,32}}=65
\end{gathered}
$$

\section{Isolated optimization - producer}

The producer wants the supplement to be connected with minimal costs of order and semi-products storing:

$$
\begin{gathered}
N_{v}=f_{3} \cdot n_{v}+\frac{Q}{2 f_{3}} \cdot s_{v} \\
f_{3}=\sqrt{\frac{Q \cdot s_{v}}{2 \cdot n_{V}}}=\sqrt{\frac{90000 \cdot 1}{2.18}}=50
\end{gathered}
$$

It is obvious that the calculated optimal frequency differ $(30 \neq 65 \neq 50)$. This is the reason, why the isolated optimization cannot be performed. The economically strongest subject will enforce his interest and the others must accept it. In our case, there are three possible alternatives:

- The economically strongest is the supplier $\left(f_{1}=f_{2}=f_{3}=30\right)$

$$
\begin{aligned}
& N_{d}=f_{1} \cdot n_{d}+\frac{Q}{2 f_{1}} \cdot s_{d}=30 \cdot 40+\frac{90000}{2.30} \cdot 0,8=2400 \\
& N_{v}=\frac{A}{f_{2}} \cdot f_{2} \cdot l \cdot n_{\mathrm{t}}=\frac{54080}{30}+30 \cdot 40 \cdot 0,32=2186,68 \\
& N_{v}=f_{3} \cdot n_{v}+\frac{Q}{2 f_{2}} \cdot s_{v}=30 \cdot 18+\frac{90000}{2.30} \cdot 1=2040
\end{aligned}
$$

Total costs of the whole supply chain are in this case $6266,68 €$.

- The economically strongest is the carrier $\left(f_{1}=f_{2}=f_{3}=65\right)$

$$
\begin{gathered}
N_{d}=f_{1} \cdot n_{d}+\frac{Q}{2 f_{1}} \cdot s_{d}=65 \cdot 40+\frac{90000}{2.65} \cdot 0,8=31523,85 \\
N_{v}=\frac{A}{f_{2}} \cdot f_{2} \cdot l \cdot n_{\mathrm{t}}=\frac{54080}{65}+65.40 \cdot 0,32=1664
\end{gathered}
$$




$$
N_{v}=f_{3} \cdot n_{v}+\frac{Q}{2 f_{2}} \cdot s_{v}=65 \cdot 18+\frac{90000}{2.65} \cdot 1=1862,31
$$

Total costs of the whole supply chain are in this case $6680,16 €$.

- The economically strongest is the producer $\left(f_{1}=f_{2}=f_{3}=50\right)$

$$
\begin{gathered}
N_{d}=f_{1} \cdot n_{d}+\frac{Q}{2 f_{1}} \cdot s_{d}=50 \cdot 40+\frac{90000}{2.50} \cdot 0,8=2700 \\
N_{v}=\frac{A}{f_{2}} \cdot f_{2} \cdot l \cdot n_{\mathrm{t}}=\frac{54080}{50}+50 \cdot 40 \cdot 0,32=1721,6 \\
N_{v}=f_{3} \cdot n_{v}+\frac{Q}{2 f_{2}} \cdot s_{v}=50.18+\frac{90000}{2.50} \cdot 1=1800
\end{gathered}
$$

Total costs of the whole supply chain are in this case $6221,6 €$.

\section{Logistic optimization (minimizing costs of whole chain)}

If there is a willingness to cooperate and trade relations arise, it is possible in accordance with logistical approach to find an optimal solution for the whole chain, where the most effective is the compromise, when all subjects of supply chain have some advantage. The costs of the whole supply chain can be explained as follows:

$$
N_{\log }=f \cdot n_{d}+\frac{Q \cdot s_{d}}{2 f}+\frac{A}{f}+f \cdot l \cdot n_{\mathrm{t}}+f \cdot n_{v}+\frac{Q \cdot s_{v}}{2 f}
$$

\section{Optimal frequency of transport will be:}

$$
f_{\text {opt }}=\sqrt{\frac{Q\left(s_{d}+s_{v}\right)+2 A}{2\left(n_{d}+l . n_{\mathrm{t}}+n_{v}\right)}=\sqrt{\frac{90000(0,8+1)+2.54080}{2(40+40.8+18)}}=18,90}
$$

After mentioned calculations, total costs of the whole supply chain by the logistic optimization are $5306,31 €$.

This study shows that cost optimization of the whole supply chain has better result than any other solution based on partly optimization.

\section{Conclusion}

The above example shows that address the optimization of the logistics chain is a very important thing. Today, businesses in order to competitiveness and sustainable development seek to optimize logistics costs in all its activities. Example results is that the optimizing logistics costs is necessary throughout the logistics chain, and do not optimize isolation to only part of the logistics chain. 


\section{References}

1. H. Minken, B.G. Johansen, A logistics cost function with wxplicit transport costs. Economics of Transportation 19 (2019)

2. I. B. Hovi, G. Jordbakke, D. Pinchasik, M. Killi, E. Auråen, Variability in Transport Time and Demand for Freight Transport in Norway. Institute of Transport Economics, Oslo, Norway TØI Report 1644/2018, (2018)

3. J. E. Tyworth, A note on lead-time paradoxes and a tale of competing prescriptions. Transport. Res. Part E 109 (2018)

4. J. Gnap, M. Poliak, S. Semanova, The Issue of a Transport Mode Choice from the Perspective of Enterprise Logistics. Open Engineering 9 (2019)

5. G. Mbiydzenyuy, Impact assessments of intelligent transport system performance in a freight transport corridor. IET Intelligent Transport Systems, 25th World Congress on Intelligent Transport Systems (ITS), Copenhagen, (2018)

6. P. Fiala, J. Jablonsky, M. Manas, Vicekriterialni rozhodovani (1st ed.), (1994)

7. M. Poliak, V. Konecny, Factors determining the electronic tolling scope of road network. Journal of Economics, 36, 7, (2008)

8. WHITE PAPER, Roadmap to a Single European Transport Area - Towards a competitive and resource eflcient transport system, COM(2011) 144, Brussel

9. M. Poliak, J. Hammer, K. Cheu, M. Jaskiewicz, Identification of costs structure change in road transport companies. Communications, (2019)

10. M. Poliak, J. Hammer, N. Reuter, A. Poliakova, The impact of the transport route on the cost of the transfer. Automotive Safety, (2018)

11. Majercak, J. Kudlac, S. Panak, M, Sustainable and Economically efficient Five-point Supply Chain Management. Transport Means, (2016)

12. Majercak, P. Majercak, J. Logistics indicatiors for Measuring Performance of Logistics System in the Company. ERMI (2015)

13. Babin, M. Buda, M. Majercak, J. Railway companies and legislation scheme in Transportation of Dangerous Goods. Transport Means (2012)

14. Babin, M. Buda, M. Majercak, J. Terminals for Transportation of Dangerous Goods. Transport Means (2012)

15. Nedeliakova, E. Stefancova, V. Kuka, A. Innovative methodology for quality and risk management in logistics processes of transport undertakings. Business logistics in modern management. Osijek (2018) 